\title{
Perencanaan Pengembangan Lanskap Jalan Teuku Umar Barat, Kota Denpasar, Bali
}

\author{
Aisyah Dian Anjelika ${ }^{1}$, Ni Wayan Febriana Utami ${ }^{*}$, I Made Sukewijaya ${ }^{2}$
}

1. Prodi Arsitektur Lanskap, Fakultas Pertanian, Universitas Udayana, Jl. P.B. Sudirman, Denpasar, Indonesia

2. Prodi Agroekoteknologi, Fakultas Pertanian, Universitas Udayana, Jl. P.B. Sudirman, Denpasar, Indonesia

`E-mail: wayan_febriana@unud.ac.id

\begin{abstract}
Landscape Development Planning At Teuku Umar Barat Street, Denpasar City, Bali. Teuku Umar Barat street is a collector type of street located in Denpasar City, Bali. High level activities in Teuku Umar Barat street without being accompanied by a good division of space will resulting inconvenience for users. It is also aggravated by the absence of structure and procurement of street facilities. Hence, it needs to be planned to achieve the main function of Teuku Umar Barat street. This study aims to identify the existing condition of Teuku Umar Barat street and to plan it by implementing sustainable streetscape approach. The method used in this research was field survey by conducting observation, interview, and literature study. There were four stages conducting in this research i.e. inventory, analysis, synthesis, and planning. The result of this study showed that the planning applied was natural and cultural resource approach. The sustainable streetscape resulted was planned to provide an optimal balance between community and commercial interests by ensuring the continuity of its existence.
\end{abstract}

Keywords: The Teuku Umar Barat Street, sustainable streetscape, streetscape, landscape development planning

\section{Pendahuluan}

Jalan adalah prasarana transportasi darat yang meliputi segala bagian jalan, termasuk bangunan pelengkap dan perlengkapannya yang diperuntukkan bagi lalu lintas, yang berada pada permukaan tanah, di bawah permukaan tanah, di atas permukaan tanah dan atau air, serta di atas permukaan air, kecuali jalan kabel, jalan kereta api, dan jalan lori (UU No.34, 2006). Jalan Teuku Umar Barat merupakan salah satu jalan kolektor yang terletak di Kota Denpasar dengan lalu lintas harian rata-rata 42.109 smp/jam (Wikrama, 2011). Jalan ini merupakan akses menuju pusat Kota Denpasar ataupun lokasi wisata yang terletak di daerah Canggu, Kuta, dan sekitarnya.

Jalan Teuku Umar Barat merupakan kawasan perdagangan dan jasa yang kondisi lanskap nya dapat dikatakan kurang tertata dengan baik dan tampak tidak menarik secara visual. Hal ini terlihat dari aspek biofisik dan sosial budaya yang ada di Jalan Teuku Umar Barat. Permasalahan dari aspek biofisik yang terlihat yaitu tidak tersedianya fasilitas pegguna jalan seperti jalur pedestrian yang layak, penerangan yang cukup, serta minim vegetasi. Sedangkan dari aspek sosial budaya yaitu belum adanya penataan ruang seperti tidak ada batas yang jelas antara jalur untuk berjalan kaki dan berkendara serta tidak memiliki nilai identitas kebudayaan Bali. Menurut Hakim dan Utomo, (2003) kenyamanan adalah segala sesuatu yang memperlihatkan penggunaan ruang secara harmonis dan sesuai, baik dengan ruang itu sendiri maupun dengan berbagai bentuk, warna, tekstur, bau, suara, atau lainnya. Faktor-faktor yang mempengaruhi kenyamanan yaitu sirkulasi, bentuk, kebisingan, keamanan, aroma, kebersihan, keindahan, dan iklim.

Perencanaan pengembangan lanskap di Jalan Teuku Umar Barat perlu dilakukan untuk mempertahankan dan memperbaiki fungsi serta kenyamanan jalan dengan mengidentifikasi potensi dan kendala dari aspek biofisik dan aktivitas. Hasil dari studi berupa perencanaan pengembangan lanskap jalan yang diharapkan dapat menjadi bahan masukan dan pertimbangan bagi pihak perencana maupun pengelola Jalan Kota Denpasar. 


\section{Metode}

\subsection{Tempat dan Waktu Penelitian}

Penelitian berlokasi di Jalan Teuku Umar Barat sepanjang $2 \mathrm{~km}$ membentang dari timur ke barat. Secara administratif, lokasi penelitian terletak di Kelurahan Dauh Puri Klod, Kecamatan Denpasar Barat, Kota Denpasar, Provinsi Bali (Gambar 1). Penelitian ini berlangsung selama 15 bulan mulai dari bulan November 2018 sampai dengan bulan Februari 2020.

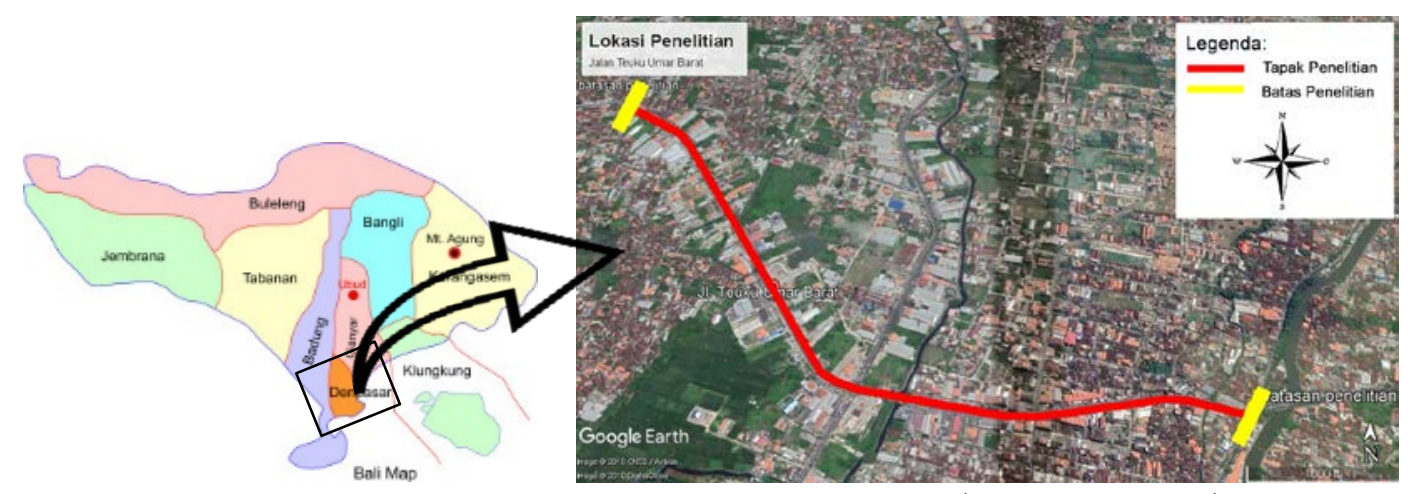

Gambar 1. Lokasi Penelitian di Jalan Teuku Umar Barat (Google Earth, 2018)

\subsection{Alat dan Bahan}

Alat dan bahan yang digunakan dalam pelaksanaan penelitian yaitu, meteran, buku, alat tulis, kamera, lembar wawancara, laptop dengan piranti lunak Microsoft Word, Microsoft Excel, AutoCAD, Adobe Photoshop, Google Earth, ArcGIS, dan sound meter.

\subsection{Metode Penelitian}

Metode yang digunakan adalah seperti yang dikemukakan oleh Simonds, (1983) yang meliputi tahap commission, research, analysis, synthesis, construction, dan operation. Pada studi ini dimulai dari kegiatan research (penelitian) dan dibatasi hingga tahapan perencanaan yang tercakup dalam synthesis (sintesis). Untuk metode pengambilan data yang digunakan dalam penelitian ini adalah survei, dengan teknik pengambilan data antara lain observasi, wawancara, dan studi pustaka. Observasi dilakukan untuk menggambarkan data kondisi umum Jalan Teuku Umar Barat, fasilitas jalan, foto lanskap, serta data kebisingan. Wawancara dilakukan menggunakan metode purposive sampling, dengan responden yaitu lakilaki dan perempuan berjumlah 20 orang dengan rentang usia 20-50 tahun yang terdiri dari sepuluh orang pemiliki ruko ataupun masyarakat yang tinggal di sepanjang tapak penelitian, lima orang merupakan pengguna jalan yang pernah melintasi Jalan Teuku Umar Barat serta lima orang yang mewakili instansi terkait seperti Dinas Perumahan, Kawasan Permukiman, dan Pertanahan Kota Denpasar Divisi Pertamanan, Dinas Pekerjaan Umum dan Penataan Ruang Kota Denpasar, Dinas Perhubungan Kota Denpasar, Dinas PU Bina Marga Provinsi Bali, dan Dinas Lingkungan Hidup Kota Denpasar. Selain itu, dihitung juga penilaian terhadap indeks kenyamanan (THI) dengan rumus :

$$
T H I=0,8 \mathrm{~T}+(\mathrm{RH} \times \mathrm{T} / 500)
$$

$$
\begin{aligned}
& \text { Keterangan: } \\
& \text { THI= temperature humidity index } \\
& \mathrm{T}=\text { suhu atau temperatur udara }\left({ }^{\circ} \mathrm{C}\right) \\
& \mathrm{RH}=\text { kelembaban udara (\%) }
\end{aligned}
$$

\section{Hasil dan Pembahasan}

\subsection{Gambaran Umum Lokasi Penelitian}

Jalan Teuku Umar Barat terletak di Kecamatan Denpasar Barat, Kota Denpasar. Secara geografis,

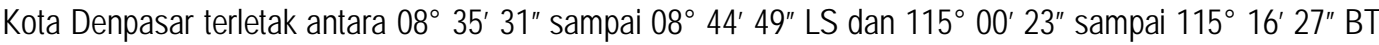


dengan panjang jalan 3,2 km (Kementrian Pekerjaan Umum dan Perumahan Rakyat, 2004). Penelitian dilakukan sepanjang $2 \mathrm{~km}$ dimulai dari persimpangan Jalan Teuku Umar Barat - Imam Bonjol (batas timur) sampai persimpangan Jalan Teuku Umar Barat - Tangkuban Perahu (batas barat) dengan lebar jalan yang bervariasi yaitu $20-25 \mathrm{~m}$. Lokasi penelitian yang dipilih adalah Jalan Teuku Umar Barat yang memiliki lebar minimal $20 \mathrm{~m}$.

Jalan Teuku Umar Barat berfungsi sebagai jalur perbatasan antara jalan provinsi dan jalan kota. Jalan provinsi pada wilayah penelitian terletak di Desa Pemecutan Klod, Denpasar Barat. dengan panjang jalan 0,85 $\mathrm{km}$. Jalan kota pada wilayah penelitian terletak di Desa Padang Sambian Klod, Denpasar dengan panjang jalan 1,17. Berdasarkan UU No. 22 tahun 2009 tentang lalu lintas dan angkutan jalan, kelas jalan provinsi dan jalan kota di tapak penelitian ini termasuk kelas jalan III.

\subsection{Inventarisasi}

\subsubsection{Aspek Biofisik}

\subsubsection{Topografi}

Kondisi topografi di Kota Denpasar secara umum miring ke arah selatan dengan ketinggian berkisar antara 0-75 $\mathrm{m}$ dpl. Jenis tanah di Kota Denpasar adalah tanah mediteran yang kurang peka terhadap erosi (Pemerintah Daerah Kota Denpasar, 2019). Jalan Teuku Umar Barat berada pada ketinggian 10 - $22 \mathrm{~m}$ dpl, kondisi jalan secara umum yaitu datar dan lurus. Pada tapak penelitian terdapat tiga badan air yaitu dua Tukad Mati di jalan provinsi dan satu Tukad Ayung di jalan kota.

\subsubsection{Iklim}

Kota Denpasar termasuk daerah beriklim tropis yang dipengaruhi angin musim sehingga memiliki musim kemarau dengan angin timur dan musim hujan dengan angin barat dan diselingi oleh musim pancaroba. Suhu udara rata-rata Kota Denpasar selama 10 tahun dari tahun 2009 hingga tahun 2018 yakni $27,6^{\circ} \mathrm{C}$. Kelembaban udara rata-rata Kota Denpasar selama 10 tahun dari tahun 2009 hingga tahun 2018 adalah 78,8\% (BMKG Kota Denpasar, 2018). Berdasarkan perhitungan indeks kenyamanan, Kota Denpasar memiliki nilai THI $26,4^{\circ} \mathrm{C}$ sehingga Kota Denpasar tergolong cukup nyaman (Emmanuel, 2005).

\subsubsection{Fasilitas}

Berdasarkan pengamatan di sepanjang tapak penelitian, dapat dijumpai beberapa fasilitas jalan seperti lampu penerangan jalan, lampu lalu lintas, rambu lalu lintas, garis marka jalan, jalur pejalan kaki, dan median jalan. Kondisi fisik fasilitas jalan seperti lampu lalu lintas, lampu penerangan jalan, rambu lalu lintas, dan garis marka jalan dalam keadaan baik. Namun, beberapa fasilitas dalam kondisi tidak baik seperti konstruksi jalur pejalan kaki rusak, drainase dipenuhi sampah dan tumbuhan liar, serta median jalan yang terbengkalai sehingga perlu adanya perbaikan pada fasilitas tersebut.

\subsubsection{Kebisingan}

Sumber bunyi yang terdapat di tapak berasal dari lalu lintas kendaraan dan suara satwa. Data kebisingan pada tapak penelitian yang disebabkan oleh lalu lintas berbeda pada masing-masing area. Berdasarkan hasil pengukuran tingkat kebisingan pada tapak penelitian, area pada ruas jalan provinsi melebihi baku kebisingan yang telah ditetapkan oleh Menteri Negara Lingkungan Hidup, (1996). Pada area perdagangan dan jasa, tingkat kebisingan mencapai $72 \mathrm{~dB}$ sedangkan baku kebisingan yaitu $70 \mathrm{~dB}$. Adapun untuk area Kesehatan, tingkat kebisingan mencapai $56 \mathrm{~dB}$ sedangkan baku kebisingan yaitu $55 \mathrm{~dB}$. Hal ini diakibatkan oleh tingginya aktivitas manusia dan kendaraan di area tersebut. Tingkat kebisingan pada ruas jalan kota berada di bawah tingkat baku kebisingan dengan rata rata tingkat kebisingan $56 \mathrm{~dB}$. Menurut Fitriyati, (2005) vegetasi mampu menyerap dan menghalangi kebisingan sehingga membuat lingkungan lebih nyaman. Kapasitas peredaman kebisingan oleh vegetasi tergantung pada jenis vegetasi, kerapatan, kerimbunan, lokasi, dan frekuensi bunyi.

\subsubsection{Vegetasi}

Vegetasi yang banyak ditemui di sepanjang jalan ini merupakan hasil penanaman yang dilakukan oleh Dinas Perumahan, Permukiman dan Pertanahan Kota Denpasar Divisi Pertamanan. Terdapat sepuluh jenis tanaman pohon yang ditanam di sepanjang jalan tapak penelitian yaitu pohon jambu (Syzygium aqueum), mahoni (Swietenia mahagoni), kelapa (Cocos nucifera), bintaro (Cerbera manghas), kersen (Muntingia calabura), palem raja (Roystonea regia), kamboja (Plumeria sp.), bugenvil (Bougainvillea spectabilis), 
Ketapang (Terminalia catappa), dan angsana (Pterocarpus indicus). Jumlah pohon yang ditanam di jalan provinsi adalah 43 pohon dan di jalan kota 147 pohon. Jenis vegetasi yang mendominasi pada tapak penelitian yakni pohon mahoni (Swietenia mahagoni). Penanaman dilakukan di tepi jalan dan di median jalan, namun kondisi vegetasi yang ada di median jalan telah kering dan mati. Menurut McCluskey (1992), dalam Ginting dan Pohan (2017) tanaman memiliki banyak kegunaan dalam kaitannya dengan jalan yaitu, fungsi ekologis, fungsi teknik, dan fungsi arsitektural. Hal ini membuat penataan vegetasi pada ruang jalan sangat penting dilakukan untuk menciptakan kenyamanan bagi pengguna jalan di sekitar tapak penelitian.

\subsubsection{Satwa}

Berdasarkan hasil studi, ditemukan beberapa jenis burung yang banyak menghuni pohon-pohon besar seperti burung tekukur (Spilopelia chinensis), burung gereja (Passeridae), dan burung pipit (Estrildidae). Adapun satwa liar lainnya yang dijumpai di lokasi studi seperti kucing, anjing, dan serangga-serangga kecil. Sedangkan terdapat juga serta hewan ternak yang dilepas oleh pemiliknya untuk makan di sekitar lahan kosong yang berada di jalan kota seperti sapi dan babi.

\subsubsection{Sosial Budaya}

\subsubsection{Aktivitas Masyarakat Setempat}

Berdasarkan hasil pengamatan, aktivitas yang sering dilakukan oleh masyarakat setempat baik di jalan kota ataupun jalan provinsi saat pagi hari yaitu joging dan bersepeda, dimana mereka menggunakan badan jalan sebagai jalur aktivitasnya dikarenakan belum tersedianya jalur pedestrian dan jalur sepeda di jalan ini. Hal ini tentu membahayakan bagi pengguna jalan lainnya sehingga perlu diadakan jalur pedestrian ataupun jalur sepeda di sepanjang tapak penelitian. Aktivitas masyarakat yang mendominasi adalah perdagangan dan jasa yang meningkat saat sore hingga malam hari.

\subsubsection{Preferensi Masyarakat}

Guna mengetahui keinginan masyarakat sekitar, pengguna jalan, serta pendapat pemerintah terhadap keberadaan jalan ini, maka dilaksanakan wawancara terbuka kepada 20 orang (Gambar 2). Berdasarkan hasil wawancara diketahui bahwa dominan masyarakat dan pengguna menghendaki fasilitas atau perabot jalan seperti tempat sampah, lampu penerangan, trotoar, perbaikan drainase, jalur hijau, dan pelebaran jalan. Oleh karena itu akan diupayakan rencana fasilitas yang mampu mengakomodasikan keinginan tersebut namun tetap sesuai dengan kondisi tapak.

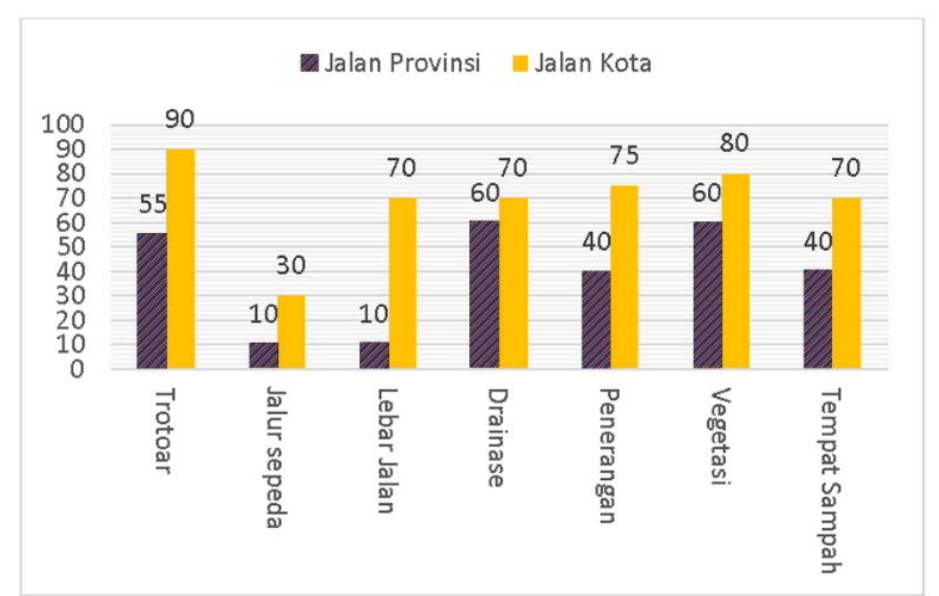

Gambar 2. Preferensi Masyarakat terhadap Jalan Teuku Umar Barat

\subsection{Analisis Potensi dan Permasalahan}

Tapak penelitian dalam RTRW Kota Denpasar, merupakan area perdagangan dan jasa di mana lokasi ini juga berdekatan dengan salah satu pusat perekonomian Kota Denpasar Barat yang terletak di Jalan Teuku Umar. Bentuk tapak penelitian berupa jalan yang di dalamnya terjadi pergerakan dan sirkulasi yang cukup tinggi menjadikan kawasan ini mempunyai posisi yang cukup strategis untuk dikembangkan. Tingkat aktivitas perdagangan dan jasa yang tinggi serta merupakan akses menuju lokasi wisata menjadikan lokasi tapak 
penelitian perlu dilakukan perencanaan pengembangan lanskap agar memiliki identitas dan karakter yang kuat sesuai dengan kebudayaan Bali.

Mewujudkan Jalan Teuku Umar Barat sebagai lanskap jalan yang berkelanjutan tentu memiliki berbagai kendala dalam pengembangan potensi yang ada. Setelah dilakukan pengamatan langsung di lapangan, permasalahan yang ada di tapak penelitian terlihat dari kondisi biofisik tapak seperti minimnya fasilitas jalan, perlunya penataan dan penambahan vegetasi, serta tidak adanya pembagian ruang antara sirkulasi pejalan kaki dengan sirkulasi kendaraan bermotor. Selain itu, Jalan Teuku Umar Barat belum memiliki identitas kebudayaan Bali.

\subsection{Sintesis}

Berdasarkan hasil inventarisasi dan analisis tapak, perencanaan lansekap sangat penting untuk dilakukan agar potensi-potensi yang dimiliki pada tapak penelitian dapat dikembangkan dan permasalahan yang ada dapat diatasi, sehingga jalan ini dapat menjadi lanskap Jalan Teuku Umar Barat yang berkelanjutan. Analisis dan sintesis Jalan Teuku Umar Barat dapat dilihat pada Tabel 3.

Tabel 3. Analisis dan Sintesis Jalan Teuku Umar Barat

\begin{tabular}{|c|c|c|c|c|}
\hline \multirow{2}{*}{ No } & \multirow{2}{*}{ Aspek } & \multicolumn{2}{|r|}{ Analisis } & \multirow{2}{*}{ Sintesis } \\
\hline & & Potensi & Kendala & \\
\hline 1 & $\begin{array}{l}\text { Aksesibilitas } \\
\text { dan Lokasi } \\
\text { tapak }\end{array}$ & $\begin{array}{l}\text { Lokasi dekat } \\
\text { dengan pusat } \\
\text { perekonomian Kota } \\
\text { Denpasar dan objek } \\
\text { wisata lainnya. }\end{array}$ & $\begin{array}{l}\text { Tidak tersedia bahu jalan } \\
\text { pada jalan provinsi. Lebar } \\
\text { bahu jalan di jalan kota } \\
\text { lebarnya bervariasi. }\end{array}$ & $\begin{array}{l}\text { Memaksimalkan damaja yang tersedia } \\
\text { dan melakukan pemerataan bahu jalan } \\
\text { di jalan kota. }\end{array}$ \\
\hline 2 & $\begin{array}{l}\text { Geologi dan } \\
\text { Jenis Tanah }\end{array}$ & $\begin{array}{l}\text { Jenis tanah } \\
\text { mediterian }\end{array}$ & Kesuburan tanah. & $\begin{array}{l}\text { Penanaman vegetasi sesuai jenis } \\
\text { tanah. }\end{array}$ \\
\hline 3 & Topografi & Cenderung datar & $\begin{array}{l}\text { Saat musim hujan, terlihat } \\
\text { air yang menggenang di } \\
\text { badan jalan. }\end{array}$ & $\begin{array}{l}\text { Pembuatan kemiringan badan jalan } \\
\text { sebesar } 2 \% \text {. }\end{array}$ \\
\hline 4 & Iklim & $\begin{array}{l}\text { Suhu pada tapak } \\
\text { penelitian termasuk } \\
\text { dalam kategori } \\
\text { hangat nyaman }\end{array}$ & $\begin{array}{l}\text { Suhu saat siang hari } \\
\text { mencapai } 29,7^{\circ} \mathrm{C} \text {. }\end{array}$ & $\begin{array}{l}\text { Meletakkan vegetasi di sepanjang } \\
\text { jalan dan median jalan sebagai } \\
\text { pengatur iklim mikro. }\end{array}$ \\
\hline 5 & Vegetasi & Beraneka ragam & $\begin{array}{l}\text { Penataan serta fungsi } \\
\text { vegetasi kurang optimal. }\end{array}$ & $\begin{array}{l}\text { Mempertahankan dan meningkatkan } \\
\text { jenis vegetasi untuk fungsi ekologis } \\
\text { dan estetika. }\end{array}$ \\
\hline 6 & $\begin{array}{l}\text { Tata guna } \\
\text { lahan }\end{array}$ & $\begin{array}{l}\text { Lahan terbangun } \\
\text { dan lahan tidak } \\
\text { terbangun }\end{array}$ & $\begin{array}{l}\text { Pada lahan yang belum } \\
\text { terbangun dijadikan } \\
\text { sebagai tempat } \\
\text { pembuangan sampah } \\
\text { sehingga mengganggu } \\
\text { visual. }\end{array}$ & $\begin{array}{l}\text { Mengoptimalkan kawasan tersebut } \\
\text { menjadi area perdagangan dan jasa } \\
\text { sesuai dengan RTRW Kota Denpasar. }\end{array}$ \\
\hline 7 & Fasilitas & $\begin{array}{l}\text { - Lampu jalan } \\
\text { - Lampu lalu lintas } \\
\text { - Jalur pedestrian } \\
\text { - Marka jalan } \\
\text { - Rambu lalu } \\
\text { lintas } \\
\text { - Garis marka } \\
\text { jalan } \\
\text { - Median jalan } \\
\text { - Papan informasi } \\
\text { dan peringatan }\end{array}$ & $\begin{array}{l}\text { Median jalan tidak } \\
\text { berfungsi optimal. } \\
\text { Terdapat kerusakan } \\
\text { konstruksi trotoar dan } \\
\text { trotoar belum tersedia di } \\
\text { jalan kota. Tidak } \\
\text { tersedianya tempat } \\
\text { sampah. Tempat parkir } \\
\text { belum tertata dengan } \\
\text { baik. }\end{array}$ & $\begin{array}{l}\text { Menambah sarana dan prasarana } \\
\text { jalan dan memperbaiki fasilitas yang } \\
\text { ada. }\end{array}$ \\
\hline
\end{tabular}




\begin{tabular}{|c|c|c|c|c|}
\hline \multirow{2}{*}{ No } & \multirow{2}{*}{ Aspek } & \multicolumn{2}{|r|}{ Analisis } & \multirow{2}{*}{ Sintesis } \\
\hline & & Potensi & Kendala & \\
\hline 8 & $\begin{array}{l}\text { Sosial } \\
\text { Budaya }\end{array}$ & $\begin{array}{l}\text { Perdagangan, } \\
\text { joging, dan } \\
\text { bersepeda }\end{array}$ & $\begin{array}{l}\text { Belum adanya penataan } \\
\text { ruang serta fasilitas } \\
\text { penunjang seperti tempat } \\
\text { parkir, dan jalur } \\
\text { pedestrian. }\end{array}$ & $\begin{array}{l}\text { Pengadaan tempat parkir off street dan } \\
\text { jalur pedestrian. }\end{array}$ \\
\hline 9 & $\begin{array}{l}\text { Jaringan } \\
\text { Utilitas }\end{array}$ & $\begin{array}{l}\text { - Drainase } \\
\text { - Listrik }\end{array}$ & $\begin{array}{l}\text { Drainase tidak berfungsi } \\
\text { optimal Kabel listrik } \\
\text { terlihat tidak tertata } \\
\text { dengan baik. }\end{array}$ & $\begin{array}{l}\text { Pembuatan drainase tertutup dan } \\
\text { peletakan kabel listrik di bawah tanah. }\end{array}$ \\
\hline 10 & Reklame & Beragam & $\begin{array}{l}\text { Ditemukan peletakan } \\
\text { reklame tidak pada } \\
\text { tempatnya (pohon dan } \\
\text { listrik). }\end{array}$ & $\begin{array}{l}\text { Pemberian ciri khas budaya Bali } \\
\text { terhadap bentuk reklame dan } \\
\text { penataan reklame sesuai dengan } \\
\text { peraturan Walikota Denpasar No. } 3 \\
\text { tahun } 2004 \text {. }\end{array}$ \\
\hline
\end{tabular}

\subsection{Konsep Dasar}

Konsep dasar dari perencanaan tapak ini adalah mewujudkan agenda Sustainable Development Goals atau pembangunan berkelanjutan yang disahkan oleh Perserikatan Bangsa-Bangsa (PBB). Pembangunan berkelanjutan memiliki tujuan pada tahun 2030 sebanyak 17 poin dan pada poin ke 11 adalah keberlanjutan kota dan komunitas (Sustainable Development Goals, 2017). Konsep yang dapat diterapkan untuk mendukung tujuan tersebut yakni lanskap jalan berkelanjutan, di mana perlunya perhatian lebih pada penggunaan lahan untuk memberikan keseimbangan optimal antara kepentingan masyarakat dan komersial. Perencanaan lanskap dilakukan dengan pendekatan sumber daya tapak dan budaya. Fungsi-fungsi pada lanskap jalan dimasukkan ke dalam konsep pengembangan yang meliputi konsep ruang, konsep sirkulasi, konsep fasilitas jalan, serta konsep tata hijau.

\subsection{Konsep Pengembangan}

Berdasarkan konsep dasar yang telah ditentukan maka konsep pengembangan pada lanskap Jalan Teuku Umar Barat yaitu dengan memperhatikan faktor keselamatan pengguna, kenyamanan, dapat memberikan efek yang menyenangkan bagi pengguna jalan serta ramah lingkungan. Sesuai dengan itu maka konsep pengembangan ini meliputi konsep ruang, konsep sirkulasi, konsep tata letak fasilitas dan utillitas, dan konsep tata hijau.

\subsubsection{Konsep Ruang}

Konsep ruang merupakan pembagian ruang berdasarkan pada karakteristik ruang yang terdapat pada tapak sesuai dengan fungsi ruang, aktivitas pemakai jalan, dan kondisi lingkungan sekitar tapak. Konsep ruang pada tapak dibagi menjadi dua bagian utama yang meliputi ruang penyangga dan ruang identitas (Gambar 3). Ruang penyangga yaitu ruang bagi vegetasi untuk menyangga kawasan sekitar dari dampak aktivitas kendaraan seperti penyerap polutan dan pencegah kebisingan. Ruang ini meliputi area penyangga pada jalur hijau tepi jalan dan median jalan. Ruang identitas adalah ruang yang memberikan kesan identitas yang kuat pada pengguna jalan terhadap tapak berupa penataan tanaman berfilosofi Bali sepanjang tepi jalan terutama pada persimpangan jalan dan peletakan patung kera khas Bali pada jembatan yang terletak di atas badan air. Pemilihan patung kera sebagai ornamen jembatan terinspirasi oleh cerita Ramayana. 


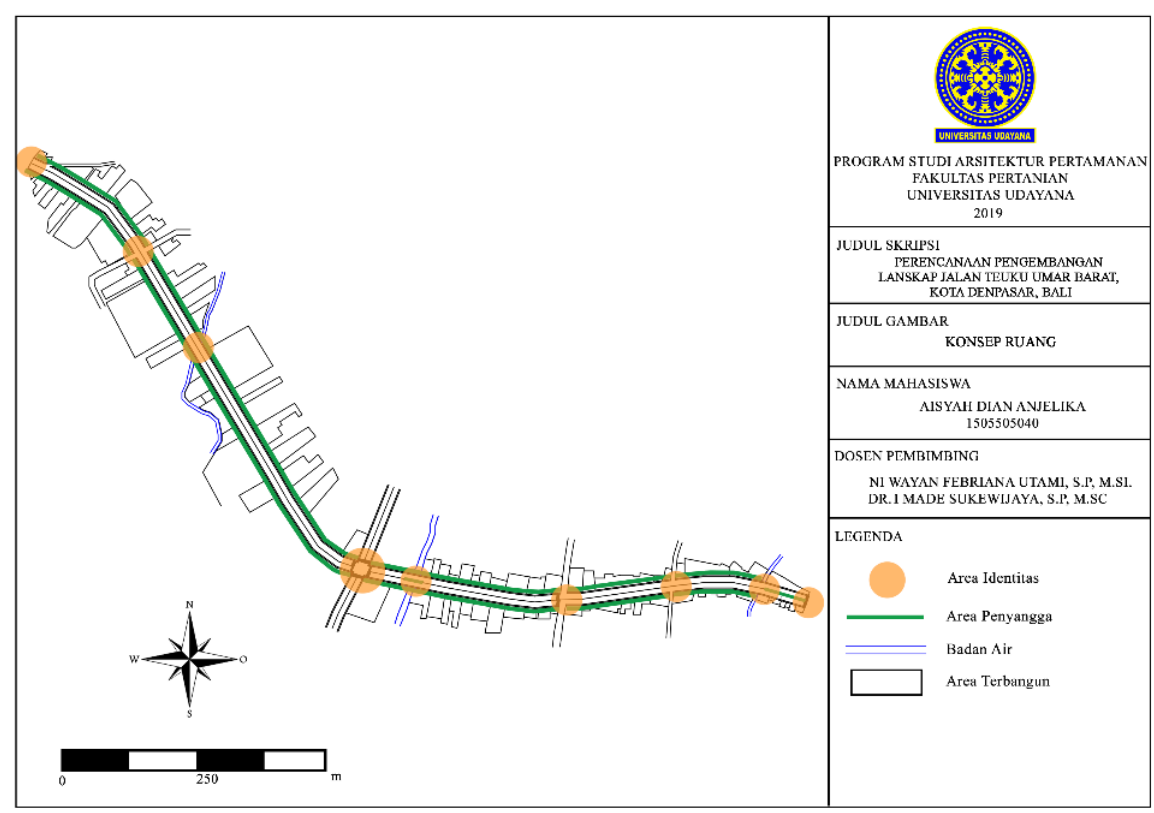

Gambar 3. Konsep Ruang

\subsubsection{Konsep Sirkulasi}

Konsep sirkulasi tetap mempertahankan atau memperkuat struktur yang ada yaitu pergerakan kendaraan dua jalur dan dua arah. Pengadaan jalur pedestrian berfungsi untuk menciptakan budaya jalan sehat dan hemat bahan bakar minyak. Konsep sirkulasi untuk pejalan kaki terbagi menjadi dua yakni primer dan sekunder. Sirkulasi primer terletak di sebelah kanan dan kiri dari bagian jalan paling luar sedangkan sirkulasi sekunder berupa pelican crossing atau zebra cross yang dilengkapi tombol pengatur lampu lalu lintas yang terletak di persimpangan Jalan Pura Demak - Kertapura.

Konsep sirkulasi untuk kendaraan adalah pergerakan yang aman, nyaman, dan lancar dengan memanfaatkan sistem jalan yang telah ada. Konsep ini dibuat demi kelancaran lalu lintas dengan mengubah konsep parkir on street menjadi off street dengan pembuatan kantong-kantong parkir di area perdagangan dan jasa yang aktivitasnya meningkat saat malam hari (Gambar 4).

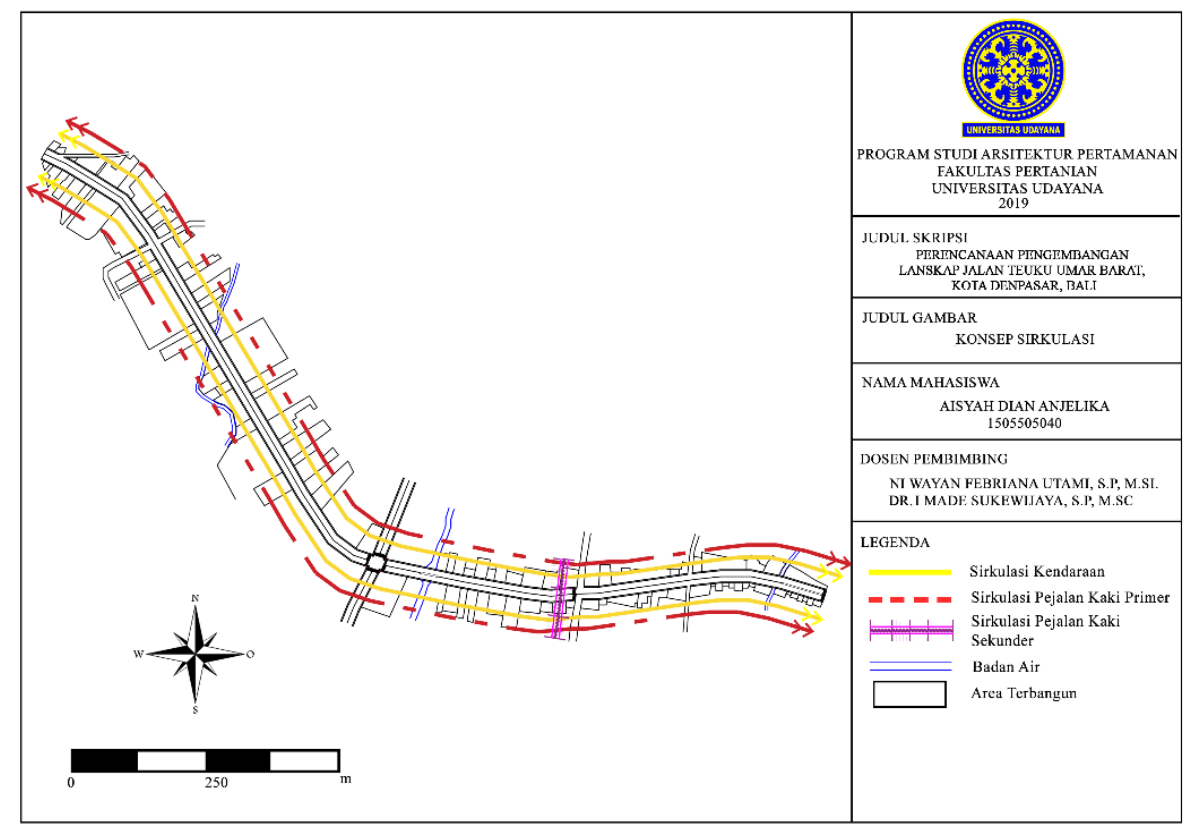

Gambar 4. Konsep Sirkulasi 


\subsubsection{Konsep Tata Letak Fasilitas dan Utilitas}

Menurut undang-undang lalu lintas nomor 14 tahun 1992 jalan wajib dilengkapi dengan rambu, marka, alat pemberi isyarat, alat pengendali dan alat pengaman pemakai jalan, alat pengawasan dan pengaman jalan, serta fasilitas pendukung lainnya. Fasilitas jalan meliputi tata informasi dan street furniture (Gambar 5).

Tata informasi pada jalan berupa rambu lalu lintas, marka, papan informasi, dan reklame. Sedangkan street furniture berupa tempat sampah, lampu penerangan, tanaman peneduh, jalur hijau jalan, tempat parkir, dan utilitas. Penggunaan street furniture berfungsi untuk memberikan keamanan dan kenyamanan bagi pengguna jalan serta memberikan keindahan pada lanskap jalan. Fasilitas jalan dibuat untuk memberikan kemudahan jangkauan, tidak mengganggu sirkulasi, dan dapat memenuhi kebutuhan penggunanya. Sedangkan dari segi estetika dimaksudkan untuk memperbaiki visual jalan.

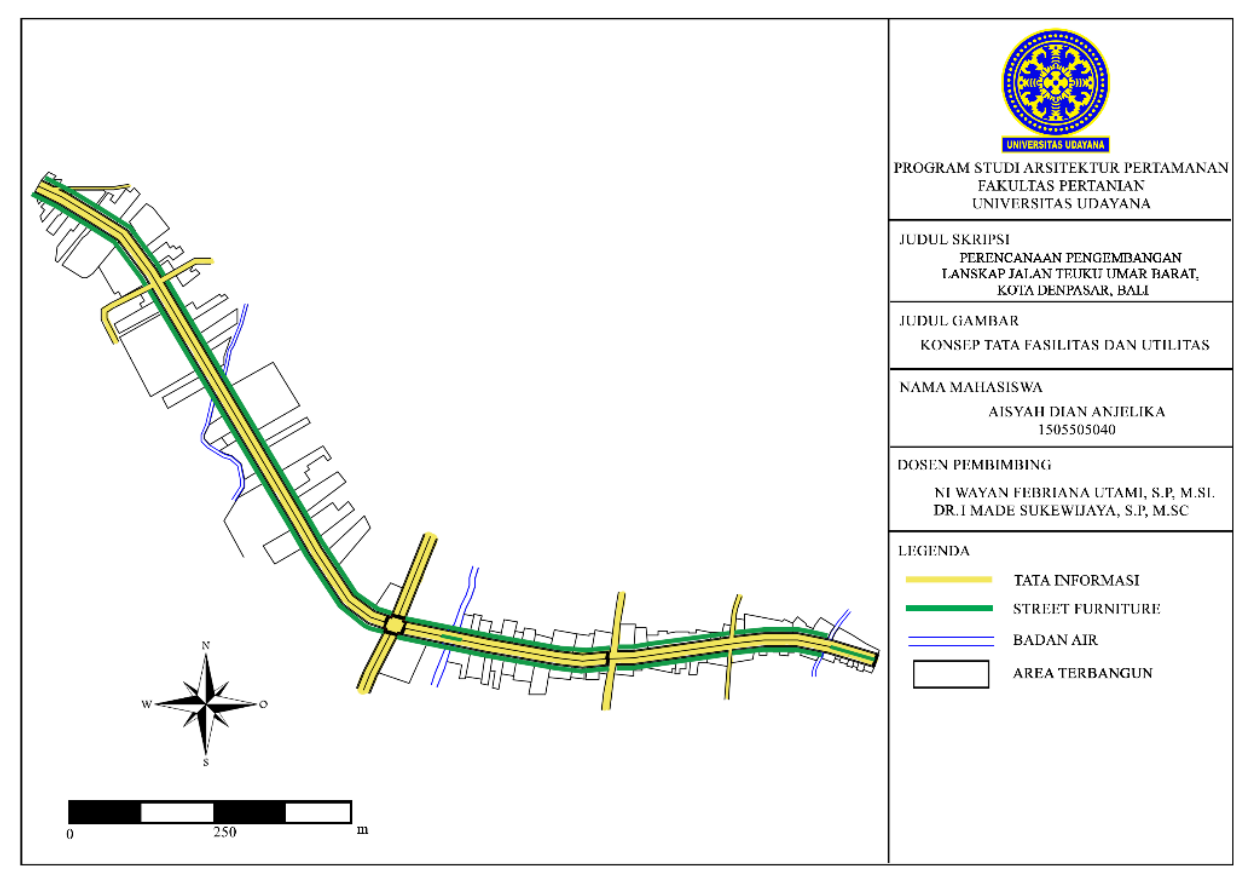

Gambar 5. Konsep Tata Fasilitas dan Utilitas

\subsubsection{Konsep Tata Hijau}

Konsep tata hijau yang dikembangkan meliputi tata hijau yang berfungsi untuk tata hijau penyangga dan tata hijau identitas (Gambar 6).Tata hijau penyangga yaitu tata hijau yang memisahkan badan jalan dengan lingkungan sekitarnya seperti pemukiman, perdagangan, dan jasa. Tata hijau ini berfungsi meredam kebisingan terutama yang disebabkan oleh kendaraan serta mengurangi polusi dari kendaran bermotor. Tata hijau identitas, yaitu tata hijau yang memberikan nilai identitas khas kebudayaan Bali dengan menggunakan konsep warna nawa sanga sebagai acuan dalam penentuan area identitas pada sepanjang jalan terutama disetiap persimpangan jalan. Nawa sanga adalah Sembilan Dewa sebagai penguasa setiap penjuru arah mata angin (Sugiarta, 2016).

Setiap arah memiliki warna suci yang terdiri dari warna putih untuk menunjukkan arah timur, warna merah untuk menunjukkan arah selatan, sedangkan warna kuning menunjukkan arah barat dan warna gelap, menunjukkan arah utara. Empat warna lainnya adalah warna merah muda yang menunjukkan arah tenggara. Warna orange menunjukkan arah barat daya, warna hijau arah barat laut, serta warna biru menunjukkan arah timur laut (Paramadhyaksa, 2016)

Warna yang diterapkan pada tapak hanya warna kuning dan putih. Di mana warna tersebut melambangkan arah barat dan timur. Penerapan konsep warna tersebut digunakan dalam pemilihan vegetasi berupa pohon dan semak. Warna yang diinginkan dapat ditonjolkan dari bagian tanaman misalnya dari bunga dan daun. 


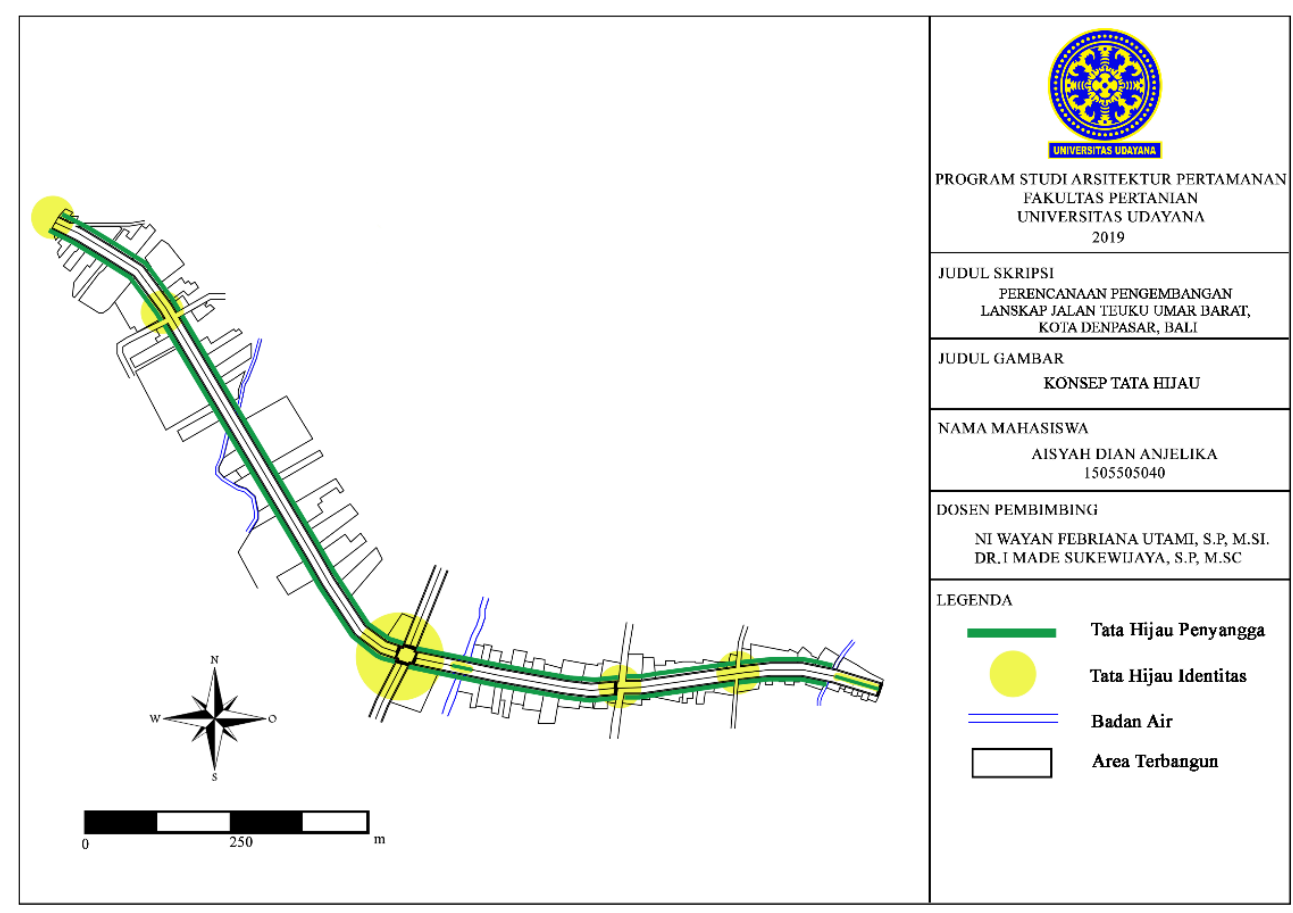

Gambar 6. Konsep Tata Hijau

\subsection{Perencanaan Lansekap}

Konsep tata ruang, sirkulasi, fasilitas, dan tata hijau yang telah dijabarkan, selanjutnya akan digambarkan dalam bentuk site plan (Gambar 7). Dari site plan tersebut dapat dilihat perencanaan lansekap Jalan Teuku Umar Barat meliputi perencanaan sirkulasi, fasilitas, dan tata hijau dengan berbagai pengembangan aktivitas dan fasilitas penunjang bagi para pengguna jalan dan masyarakat sekitar yang mendukung terciptanya Jalan Teuku Umar Barat sebagai lanskap jalan yang berkelanjutan.

\subsubsection{Rencana Sirkulasi}

Rencana ruang sirkulasi yang dikembangkan pada tapak merupakan kelanjutan dari penggunaan jalan yang telah ada. Ruang sirkulasi ini meliputi ruang pergerakan bagi kendaraan dan pejalan kaki. Ruang sirkulasi bagi kendaraan yaitu badan jalan (daerah manfaat jalan) dengan lebar $25 \mathrm{~m}$ untuk dua jalur kendaraan yang berada di sepanjang segmen jalan. Ruang khusus bagi pejalan kaki berupa trotoar yang bertujuan untuk mengurangi pemakaian kendaraan bermotor. Ruang ini terdapat di sepanjang segmen jalan dengan lebar 1,2 $\mathrm{m}$.

\subsubsection{Rencana Fasilitas}

Guna mendukung fungsi tapak yang akan direncanakan maka perlu dilakukan rencana peletakan fasilitas/perabot jalan. Fasilitas tersebut meliputi tata informasi yaitu rambu lalu lintas, papan informasi, dan papan reklame. Sedangkan untuk street furniture yaitu tempat sampah, lampu penerangan, tempat parkir, saluran drainase, dan jalur pedestrian.

\subsubsection{Rencana Tata Hijau}

Rencana tata hijau terdapat hampir di seluruh ruang yang direncanakan yaitu pada jalur hijau di median dan tepi jalan. Jalur hijau pada median dengan lebar tetap yaitu satu meter, jalur hijau tepi jalan memiliki lebar $1,2 \mathrm{~m}$ dan di setiap persimpangan akan dimaksimalkan sebagai kawasan tata hijau identitas. 


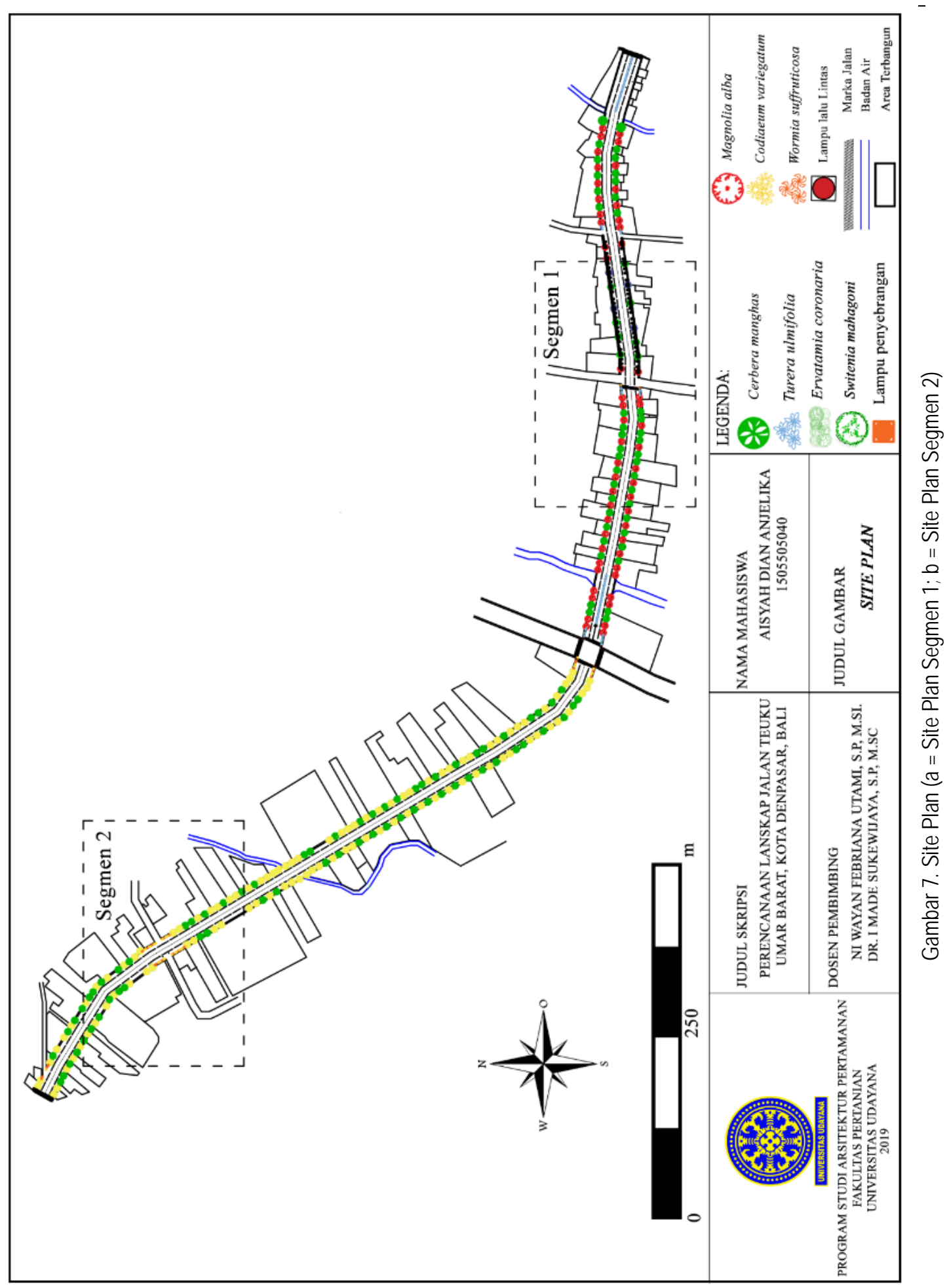




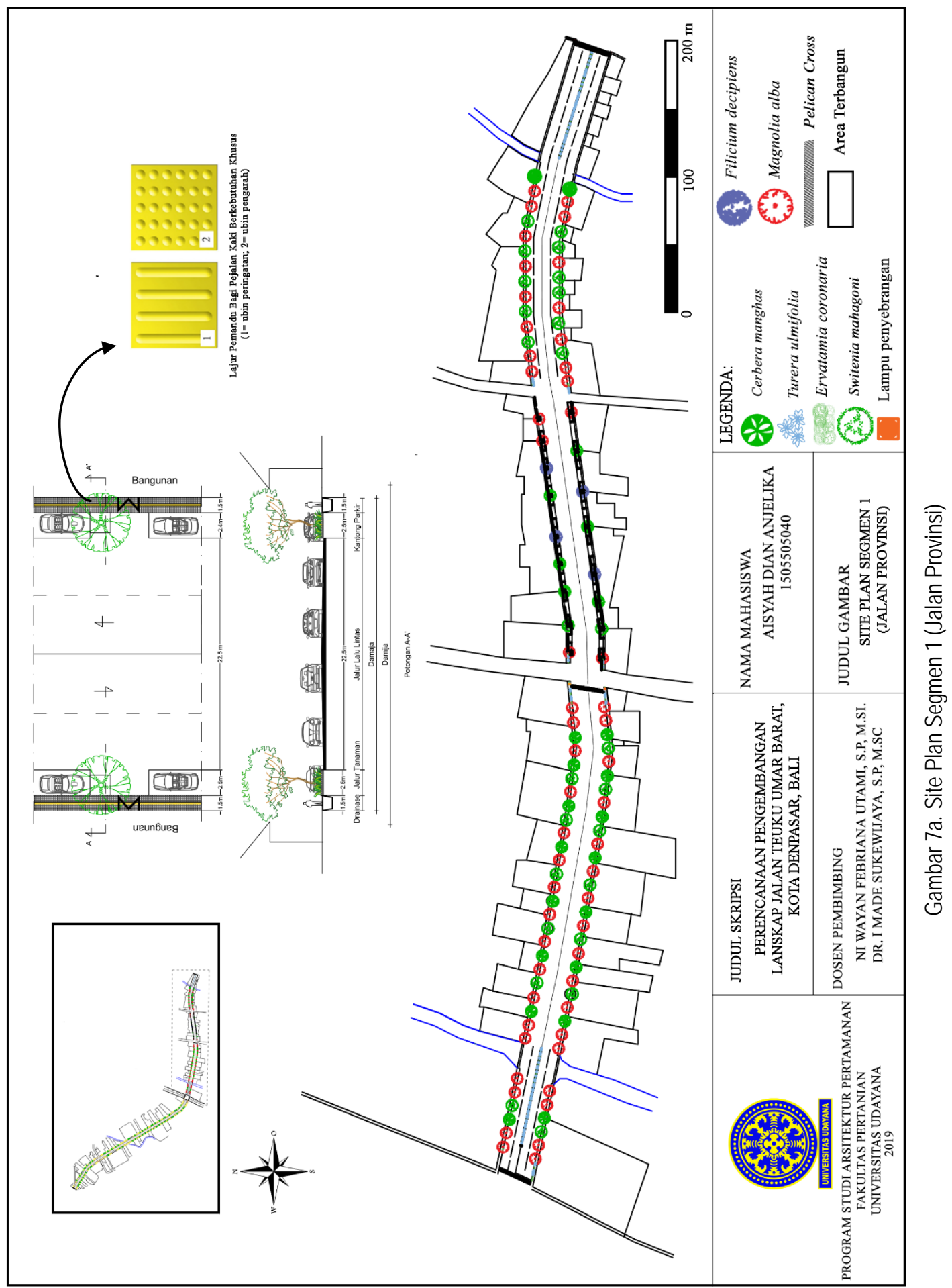




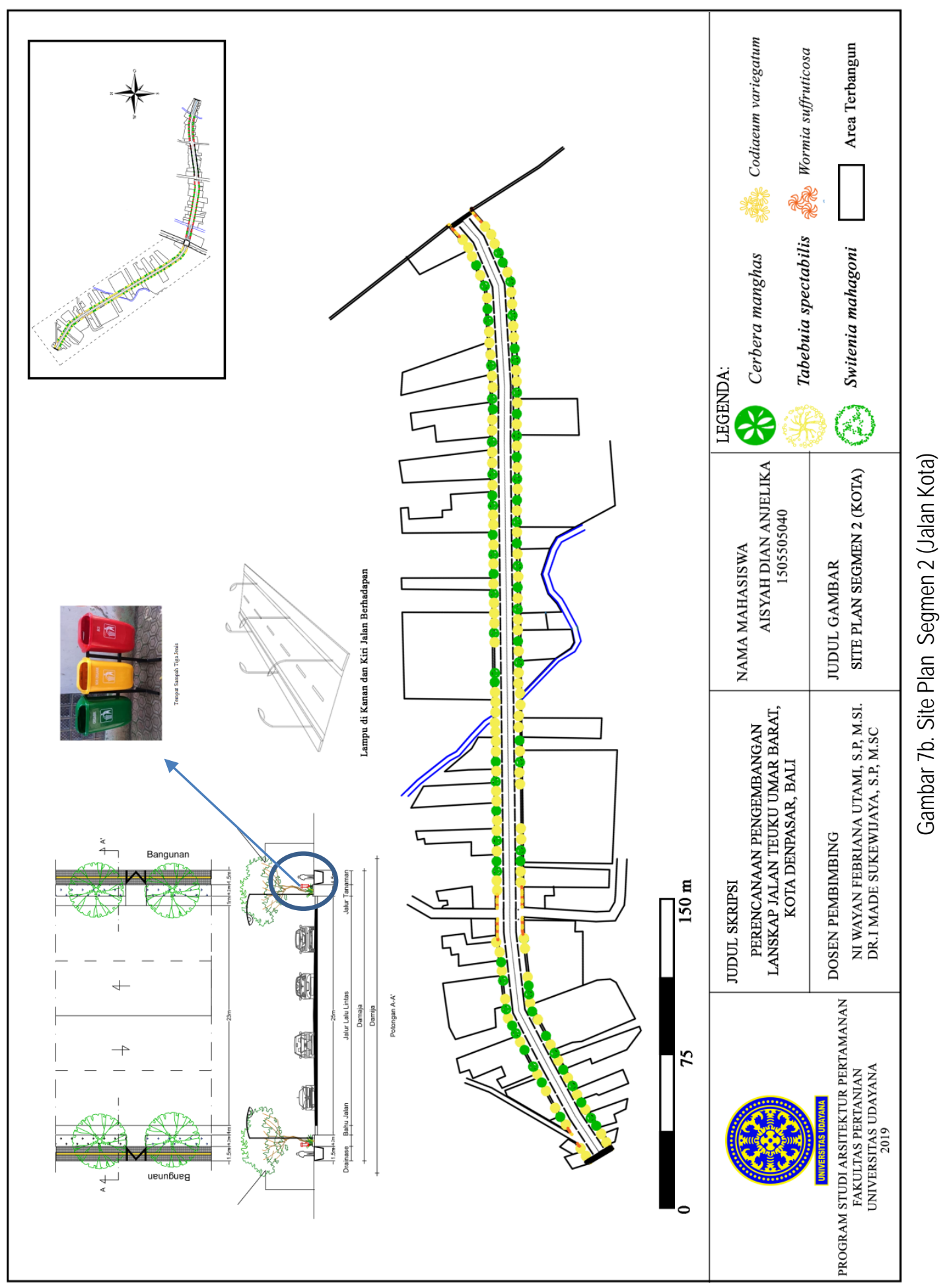

\section{Kesimpulan dan Saran}

\subsection{Simpulan}

Berdasarkan penelitian yang telah dilakukan maka dapat disimpulkan bahwa potensi yang dimiliki Jalan Teuku Umar Barat dapat dilihat dari sumber daya yang dimiliki oleh tapak seperti luas jalan dan lokasi tapak. Jalan Teuku Umar Barat merupakan area perdagangan dan jasa dengan aktivitas yang tinggi sehingga 
memiliki potensi untuk memberikan keseimbangan optimal antara kepentingan masyarakat dan komersial dengan mengusahakan kontinuitas keberadaan lanskap, masyarakat, ataupun aktivitasnya.

Kendala yang dihadapi Jalan Teuku Umar Barat dalam mewujudkan lanskap jalan yang berkelanjutan yaitu: a) Kondisi fisik fasilitas jalan yang terdapat di tapak penelitian belum mengakomodasi para pengguna jalan terutama bagi para pejalan kaki, b) Ketersediaan sistem vegetasi pada lanskap Jalan Teuku Umar Barat dikatakan minim dan belum tertata dengan baik, c) Belum adanya penataan ruang seperti tidak ada batas yang jelas antara jalur untuk berjalan kaki dan berkendara.

Konsep dasar perencanaan lanskap Jalan Teuku Umar Barat adalah "Lanskap Jalan Berkelanjutan". Konsep pengembangan dari konsep dasar tersebut terdiri dari konsep ruang, konsep sirkulasi, konsep tata fasilitas dan utilitas, serta konsep tata hijau. Rencana tata ruang terdiri dari ruang penyangga dan ruang identitas. Rencana sirkulasi meliputi sirkulasi kendaraan, sirkulasi pejalan kaki primer, dan sirkulasi pejalan kaki sekunder. Rencana tata fasilitas dan utilitas terbagi menjadi dua yakni tata informasi dan fasilitas pelengkap jalan, sedangkan rencana tata hijau yaitu kawasan penyangga dan identitas.

\subsection{Saran}

Penelitian ini dikhususkan untuk membahas mengenai perencanaan pengembangan lanskap di Jalan Teuku Umar Barat, Kota Denpasar, Bali. Oleh karena itu, perlu adanya penelitian lebih lanjut tentang desain yang dapat di terapkan pada tapak sesuai dengan analisis dan sintesis yang telah dilakukan. Sehingga dapat dijadikan sebagai masukan dan pertimbangan bagi pemerintah Kota Denpasar atau Provinsi Bali, serta pihak-pihak terkait dalam merencanakan dan mendesain lanskap Jalan Teuku Umar, Kota Denpasar, Bali.

\section{Daftar Pustaka}

Emmanuel, R. 2005. Thermal comfort implications of urbanization in a warm-humid city: the Colombo Metropolitan Region (CMR), Sri Lanka. Building and Environment. https://doi.org/ 10.1016/J.BUILDENV.2004.12.004

Fitriyati, N. 2005. Peranan Tajuk Vegetasi Sebagai Pereduksi Rising. Jurnal Lanskap Indonesia 1: 4-6.

Ginting, N \& Pohan A. F. 2017. Elemen Vegetasi dalam Penataan Ruang Kota pada Koridor Jalan Jamin Ginting Berastagi. 1048-1061.

Hakim, R \& Hardi U. 2003. Komponen Perancangan Arsitektur Lansekap Prinsip-Unsur dan Aplikasi Disain. Jakarta: Bumi Aksara.

Indonesia, R. (2006). Peraturan Pemerintah Republik Indonesia Nomor 34 Tahun 2006 Tentang Jalan. In Departemen Dalam Negeri. Jakarta.

Kementrian Pekerjaan Umum dan Perumahan Rakyat.2004. Profil Kabupaten/Kota.

Menteri Negara Lingkungan Hidup. 1996. Keputusan Menteri Negara Lingkungan Hidup Nomor: KEP 48/MENLH/11/1996 Tentang Baku Tingkat Kebisingan.

Paramadhyaksa, I. N. W. 2016. Filosofi dan Penerapan Konsepsi Bunga Padma dalam Perwujudan Arsitektur Tradisional Bali. Langkau Betang.

Simonds, J. O. 1983. Landscape Architecture: A Manual of Site Planning and Design. Mcgraw-Hill.

Sugiarta, N. 2016. Dewata Nawa Sanga dalam Agama Hindu - Mantra Hindu Bali. Tersedia online di: http://www.mantrahindu.com/11dewata-nawa-sanga-dalam-agama-hindul (diakses pada tanggal 16 februari 2020).

Wikrama, A. A. N. A. J. 2011. Analisis Kinerja Simpang Bersinyal (Studi Kasus Jalan Teuku Umar Barat-Jalan Gunung Salak). Jurnal IImiah Teknik Sipil 15(1):58-71. 